\title{
COMPARATIVE IN VITRO STUDY OF THE DIFFERENT ORTHODONTIC BRACKETS USING TWO ETCHING TECHNIQUES
}

\author{
MIHAELA PĂSTRAV ${ }^{a}$, ANDREA MARIA CHISNOIU ${ }^{b}$, \\ OVIDIU PĂSTRAV ${ }^{*}$, LAURA SILAGHI DUMITRESCU ${ }^{d}$, \\ CODRUTA SAROSI ${ }^{\mathrm{d}}$ AND VIORICA TARMURE ${ }^{\mathrm{a}}$
}

\begin{abstract}
Direct bonding of the bracket to the enamel is the elective procedure for the orthodontic treatment. Among various factors influencing the adhesive force at the enamel level, the etching technique seems to be the most important one. The present study aims at evaluating the influence of the storage media and the etching technique used, on the bond strength between different bracket types and dental structures. The results of this study showed that, regardless of the brackets and the immesion solution used, by working with the classic etch and rinse technique the adhesion force is higher than by using a self etching adhesive.
\end{abstract}

Keywords: SEM, etching technique, in vitro, adhesion

a Department of Orthodontics and Orofacial Orthopaedics, Faculty of Dental Medicine, University of Medicine and Pharmacy "Iuliu Hațieganu", 33 Motilor Street, 400001, ClujNapoca, Romania

b Department of Prosthetic Dentistry, Faculty of Dental Medicine, University of Medicine and Pharmacy "Iuliu Hatieganu", 32 Clinicilor Street, 400006, Cluj-Napoca, Romania

c *Department of Odontology and Oral Pathology, Faculty of Dental Medicine, University of Medicine and Pharmacy "Iuliu Hațieganu", 33 Motilor Street, 400001, Cluj-Napoca, Romania

d "BabesBolyai" University -"RalucaRipan" Chemistry Research Institute, 30 Fântânele Street, 400294,Cluj-Napoca, Romania.

*Corresponding author: pastravovidiu@yahoo.com 


\section{INTRODUCTION}

Direct bonding of the bracket to the enamel is the elective procedure for the orthodontic treatment. The processinvolves the enamel, the adhesive and the bracket surface, therefore, the analysis of the twointerfaces: enamel- adhesive and adhesive-bracketis an important subject of research [1]. The different physical and chemical properties of these components could establish the adhesive conditions in orthodontics [2].

There are many factors influencing de adhesive force at the enamel level, such as etching technique, adhesive application, photopolymerisation time, or mechanical properties of resin based materials for bracket bonding $[3,4]$.

The differences between the bonding forces by using selfetching adhesives or the common etching technique, followed by the use of adhesive, still represents a subject of debate[5,6].

Schnebel states that the adhesive force of the selfetching systems is not appropriate for bracket bonding and suggests that in order to gain enough bond strength orthodontists should use the classic etching technique [7]. The type of adhesive influences the bond strength, the risc of damaging the enamel and the presence of composite resin on the tooth surface [8].

The bracket type used, as well as the way the orthodontic forces are applied, influence the bond strength and the tensions that appear in the bonding layer and in the enamel $[9,10]$. Also, the enviromental factors such as soft drinks accelerate the damage of the enamel surface [11].

At the end of an orthodontic treatment the debondig of the brackets shouldn't influence the enamel surface. Though, during bracket debonding, some undesirable effects can be observed: cracks, scarring scratches, loss of enamel, adhesive scraps on the enamel surface. In addition to bracket debonding, the removal of adhesive residue with a dental bur may also lead to local enamel damage [12].

The purpose of this study was to evaluate the influence of the storage media and the etching technique used on the bond strength between bracket and dental structures.

\section{RESULTS AND DISCUSSIONS}

Table 1 shows the average values of the adhesion force for metallic, ceramic and sapphire brackets imersed in Coca Cola, tea and artificial saliva (controls). 
Table 1. Mean values of strength bond forces.

\begin{tabular}{|l|c|c|c|c|c|c|}
\hline $\begin{array}{l}\text { Immersion } \\
\text { solution }\end{array}$ & $\begin{array}{r}\text { Artificial saliva (control) } \\
{[\mathrm{MPa}]}\end{array}$ & \multicolumn{2}{c|}{$\begin{array}{c}\text { Coca Cola } \\
{[\mathrm{MPa}]}\end{array}$} & \multicolumn{2}{c|}{$\begin{array}{c}\text { Tea } \\
{[\mathrm{MPa}]}\end{array}$} \\
\hline $\begin{array}{l}\text { Etching } \\
\text { technique }\end{array}$ & $\begin{array}{c}\text { Etch } \\
\text { and rinse }\end{array}$ & Self-etch & $\begin{array}{c}\text { Etch } \\
\text { and rinse }\end{array}$ & Self-etch & $\begin{array}{c}\text { Etch } \\
\text { and rinse }\end{array}$ & Self-etch \\
\hline Bracket type & \multicolumn{3}{|c|}{} & \multicolumn{5}{|c|}{} & & \\
\hline Ceramic & $4.1 \pm 0.02$ & $4.4 \pm 0.12$ & $2.7 \pm 0.12$ & $5 \pm 0.12$ & $6.9 \pm 0.15$ & $6.6 \pm 0.07$ \\
\hline Metal & $20 \pm 0.02$ & $11.6 \pm 0.15$ & $10.7 \pm 0.11$ & $9.1 \pm 0.06$ & $29.4 \pm 0.02$ & $26.5 \pm 0.01$ \\
\hline Sapphire & $20.3 \pm 0.12$ & $10.9 \pm 0.11$ & $12.5 \pm 0.12$ & $8 \pm 0.11$ & $26.2 \pm 0.12$ & $15 \pm 0.12$ \\
\hline
\end{tabular}

The highest strength bond forces were obtained for metallic brackets, using the etch and rinse technique, for the samples immersed in tea solution $(29.4 \pm 0.02 \mathrm{MPa})$ - Table 1 .

Significant differences were observed between the groups where brackets were bonded using etch and rinse technique compared to those were self-etch technique was used $(p<0,005)$ - Table 2.

Table 2. Test statistics- Wilcoxon test

\begin{tabular}{|c|c|c|c|c|}
\hline & $\begin{array}{c}\text { Self-echting } \\
\text { technique }\end{array}$ & Ceramic & Metallic & Saphire \\
\hline$Z$ & $-3,393^{\mathrm{b}}$ & $-1,726^{\mathrm{b}}$ & $-2,981^{\mathrm{c}}$ & $-2,903^{\mathrm{c}}$ \\
\hline $\begin{array}{c}\text { Asymp. Sig. } \\
\text { (2-tailed) }\end{array}$ &, 001 &, 084 &, 003 &, 004 \\
\hline
\end{tabular}

Based on the negative value ranks we prooved that by using the classic etch and rinse technique the adhesion force is higher than by using a self etching adhesive, regardless of the immesion solution.

SEM evaluation is essential for observing the enamel surface morphology after various bonding and debonding procedures, as well as for subsequently necessity of polishing the tooth surface. The results of our investigation are based on images of the bracket bases (Figure 1) and enamel surface after bracket debonding (Figure 2, 3). Different aspects of cement debris on the enamel surface, according to the type of etching technique, are visible after debonding for all three bracket types. 


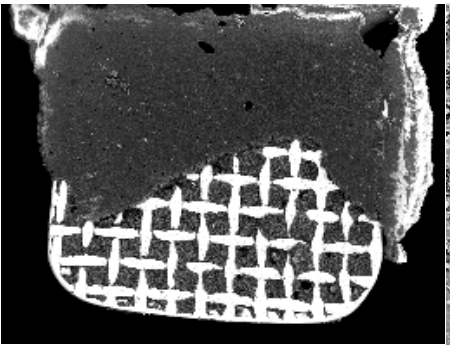

a. Metallic bracket

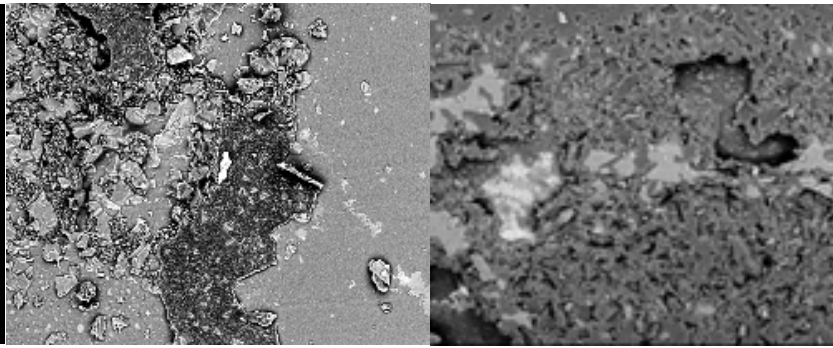

b. Sapphire bracket

c. Ceramic bracket

Figure 1. SEM images from bracket bases after debonding; 1000 magnification

The use of different materials and etching techniques can determine various degrees of wear that were observed on both the tooth surface and bracket level. The gaps and cracks of different sizes were initiated probably by the shear forces at the bracket-cement interface.

All acid etched enamel surfaces presented a porous, relatively rough aspect on SEM investigation (Figure 2a, 3a); in comparison, the selfetched enamel surfaces showed a smooth and almost clean aspect on SEM analysis (Figure $\mathbf{2 b}, \mathbf{3 b}$ ). Enamel fractures were frequently observed on tooth surfaces with brackets bonded through etch and rinse technique.

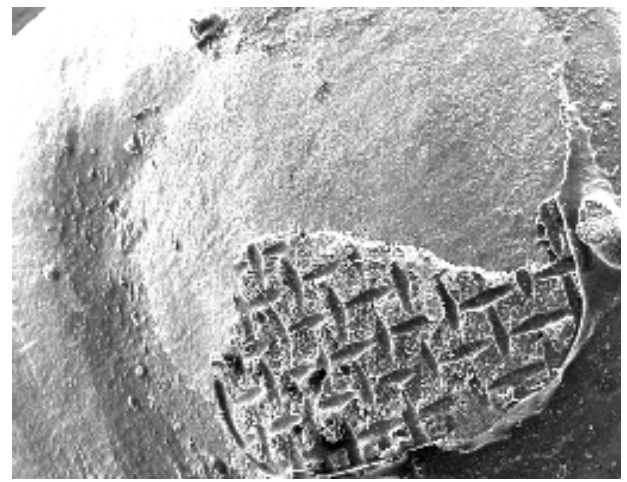

a. Metallic bracket -etch and rinse technique

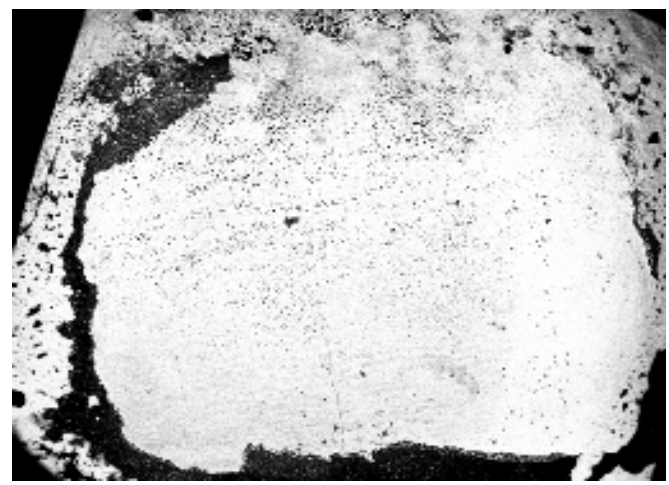

b. Metallic bracket- self-etch technique

Figure 2. SEM images of the enamel surface after metallic bracket debonding; 5000 magnification 


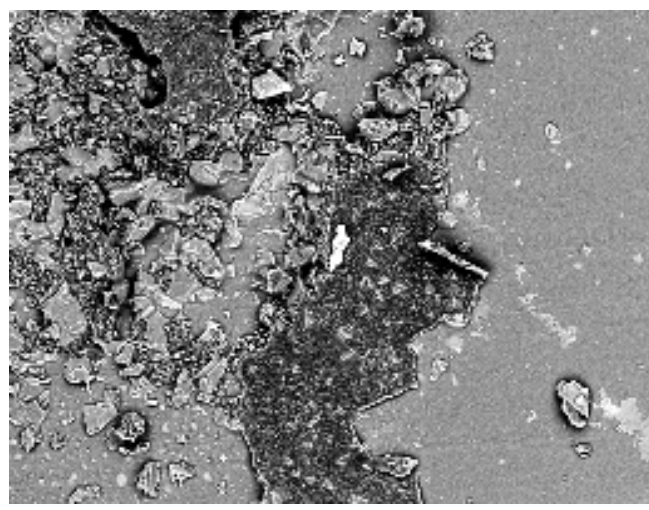

a. ceramic bracket using etch and rinse technique

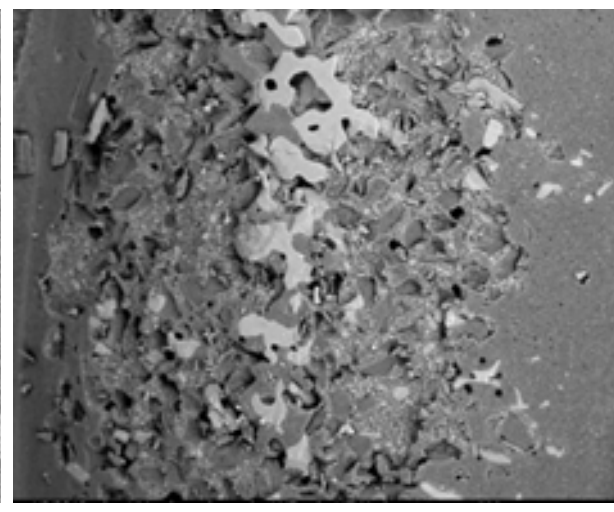

b. Sapphire bracket using selfetch technique

Figure 3. SEM images of the enamel surface after sapphire bracket debonding; 5000 magnification

Various factors can influence the bonding strength force of the brackets to the enamel such as the type of adhesive, the thickness of the adhesive layer, humidity, geometry of the bracket base,oral habits,etc, but the main one seems to be the etching technique[5-9].

The white spots observed around the brackets are mostly due to bad hygiene or the use of acidic beverages that lower the $\mathrm{pH}$ of the oral cavity [13]. Soft drinks consumption can determine erosion of the enamel and corrosion of the materials [14,15]. For this reason we used in our study, the immersion in artificial saliva, but also in Coca Cola and tea.

In our study the highest strenght forces were obtained when using the etch and rinse technique.By enlarging the adhesive surface and creating microretentions at enamel level, adequate conditions were created for adhesive penetration [1,2].

SEM images show us a significantly difference between the debonding appearance of the metallic brackets when comparing to sapphire and ceramic brackets.

In case of etch and rinse technique, after metallic bracket debonding, we can observe a relatively uniform layer of cement, both on the bracket base and on enamel. For the sapphire and ceramic brackets, the largest amount of cement seems to remain on the enamel surface.

In the case of etch and rinse technique, an almost complete distribution of the adhesive layer on the enamel surface after sapphire bracket debonding is observed, when compared to metallic brackets, where the adhesive seems to be distributed on both bracket base and enamel 
surface, in varying proportions. When self-etching adhesives are used, most cement layer remains on the enamel surface after debonding sapphire and ceramic brackets.

The concept of an ideal debonding consists of failure at the support/ adhesive interface, and the remained adhesive on the enamel surface to be carefully removed using suitable tools, in order to allow a minimum or no loss of enamel $[9,10]$. Cement debris at enamel level can favor plaque adherence, producing demineralized areas and cavities. The residual adhesive may be colored through bacteria action, or due to different alimentary pigments or cosmetics and discolorations can occur, affecting aesthetics [4]. Given the current procedures for debonding and teeth polishing, some layers of enamel could be accidentally removed causing tooth morphology changes and eventual developing of cracks [12]. Literature reports the loss of enamel ranging from 27.5 to $48 \mu \mathrm{m}$ [12], or 26.1-41.2 $\mu \mathrm{m}$ to $55.6 \mu \mathrm{m}$ [13], depending on the characteristics of the adhesive system used, the instruments or the final polishing technique. The loss of the enamel is not clinically significant compared to the average thickness of the enamel, which range from 1500 to $2000 \mu \mathrm{m}$ [12]. Finishing is considered an indispensable process to minimize enamel damage during cement removal from enamel after debonding [5, 9,12].

In vitro, orthodontic bonding is carried out in ideal conditions. In vivo, the enamel surfaces can easily be contaminated and extra humidity is sometimes unavoidable. It should be noted that, in these cases, the strength of composite resins adhesion, respectively $C=C$ covalent bonds, will decrease. Vallolah et al. [16] reported that the air at the back of the metal bracket mesh net can significantly affect complete polymerization of light-curing composite resin cements, due to the known inhibitor role of oxygen; it can alter the bond strength between metal and composite material support. But this type of failure was found only in the case of light-cured composite resin cements. Careful application of material on the support base and/or using liquid - paste systems, can avoid air entrapment. This type of failure identified at the resin - bracket interface, implies the possibility that after debonding all cement can remain on the enamel surface, which then should be cleaned. The bracket-cement interface carried out in our tests with remaining cement on both the bracket and the enamel, are partially different from the results obtained by Artun and Ozturk [17], Zarrin, Eid and Kehoe [18], which showed a higher amount of residual cement on the brackets after debonding by applying a force on the support base. The differences can be explained by the use of brackets, adhesive cements and techniques in different combinations. 
Etching time before bonding is proportional with the quantity of residual adhesive on enamel surfaces [16-18]. Fjeld et al [19] described in their study fewer irreversible changes to the enamel surface after bonding with self-etching adhesives in comparison to conventional etching.

The aspect of enamel after bracket debonding and final polishing, should be comparable to adjacent surfaces. Clinical examination of both dry and wet enamel is important because of the reflection and refraction of light, which can mask some defects on wetted surfaces of enamel [20].

No universally approved protocol has been established for adhesive resin removal after orthodontic bracket debonding, and there is no instrument that can achieve complete composite removal without affecting the enamel surface.

\section{CONCLUSIONS}

Regardless of the brackets and the immesion solution used in this study, all results indicate that by using the classic etch and rinse technique the adhesion force is higher than by using a self etching adhesive.

Metallic brackets are preferable to brackets made of monocrystalline alumina in terms of base design for minimum possible superficial destructions of enamel after debonding. Also, for the same reasons, the bonding technique using the total etch and rinse protocol seems to be a more inspired choice than the self-etching adhesives.

Using conservative instruments and techniques becomes very important, due to multiple possibilities for bracket bonding and to surface treatments that may reduce the loss of the superficial layer of enamel.

\section{EXPERIMENTAL SECTION}

Three types of brackets (metallic, ceramic and sapphire) were used. All brackets were bonded to enamel using two etching techniques (self-etch and classic) followed by adhesive application.

All samples were altered rapidly by physical and chemical stress, using several immersive solutions at body temperature. The samples from each group (metal, ceramic or sapphire) were randomly distributed in three subgroups immersed and stored for 3 month, in artificial saliva (controls), Coca Cola or tea. The strength bond force on bracket enamel interface was evaluated. 
The comparisons within the statistical part were done between the specimens with the same bracket type, immersed in the same solution, ones bonded with the self-etching technique, others using the etch and rinse technique.

By using one single bonding agent, but different etching techniques, the differences area was restricted to the bonding technique.

The bracket bondig procedure was done accordingly to the manufacturers indications and kept in artifical saliva for 24 hours.

The solutions were prepared and used as follows:

1. Black tea (The mélange angles, Breakfast Black tea)-was kept at $37^{\circ} \mathrm{C}$ for 20 minutes per day, in order to simmulate the necessary time for each person to drink a cup of tea, as well as the temperature.

2. Coca Cola- the probes were immeresed for 20 minutes per day, at $37^{\circ} \mathrm{C}$.

3. Control group for this group the probes were immersed in artificial saliva at $37^{\circ} \mathrm{C}$, in thermosthatic bath, without any other treatment.

The brackets were debonded three months after the initial moment of the experiment. Strenght bond force was evaluated out using Llyod Universal Testing machine. A sharp blade was used to apply an oclusogingival force at the bracket-adhesive interface, with a speed of $1 \mathrm{~mm} / \mathrm{min}$.

The values of the strenght bond force were mesured in MPa, using NEXYGEN Plus Materials Testing Software. The statistical analisys was performed using we used the nonparametric two-pired Wilcoxon statistic test, paired type. The specimens were also examined by using scanning electron microscopy (SEM) and energy dispersive X-ray (EDAX) spectrometry.

\section{ACKNOWLEDGEMENT}

This work was funded by the Romanian Ministry of Education and Research, National projects: PNIII-P2-2.1-PED-2016-1907 and PNIII-P2-2.1PED-2016-1415.

\section{REFERENCES}

1. M. Hashimoto, H. Ohno, E. Yoshida, M. Hori, H. Sano, M. Kaga, H. Oguchi, European Journal of Oral Science, 2003,111, 447.

2. C. Raposo, I.L. Santana, Revista Odontologia Ciencia,2012, 27,143.

3. B.C. Parrish, T.R. Katona, S.C. Isikbay, K.T. Stewart, K.S. Kula, Angle Orthodontics, 2012, 82, 131. 
4. M. Schroeder, A.C.S. Gama, A.G.V. Moares, L.C. Yamasaki, A.D. Loguercio, J. Bauer, Dental Materials, 2011, 27, 20.

5. P.S. Fleming, Evidence Based Dentistry, 2014, 15, 48.

6. A. Elkhadem, N. Orabi, Evidence Based Dentistry, 2013, 14, 52.

7. A. Schnebel, S. Mateer, A.L. Maganzini, K. Freeman, Journal of Orthodontics, 2012, 39, 256.

8. T. Lamper, N. Ilie, K. C. Huth, I. Rudzki, A. Wichelhaus, E. Paschos, Clinical Oral Investigations, 2014, 18, 313.

9. S.E. Elsaka, S. M. Hammad, N. F. Ibrahim, Progress in Orthodontics, 2014, $16,33$.

10. V. Bolaños-Carmona, B. Zein, M. Menéndez-Núñez, P. Sánchez-Sánchez, L. Ceballos-García, S. González-López, Dental Materials Journal, 2015, 34, 449.

11. J.A. von Fraunhofer, M. M. Rogers, General Dentistry, 2004, 52, 308.

12. C. Speera, D. Zimnyb, W. Hopfenmuellerc, E. Holtgrave, Angle Orthodontist, 2005, 75, 5 .

13. J.F. Tahmassebi, M.S.Duggal, G. Malik-Kotru, M.E. Curzon, Journal of Dentistry, 2006, 34, 2.

14. H.H. Yip, R.W. Wong, U. Hägg, World Journal of Orthodontics, 2009, 10, 33.

15. J.M. Steffen, Angle Orthodontist, 1996, 66, 449.

16. A. Valiollah, N. Fatemeh, R. Mehdi, K. Ahmad, Mohammad S. Barati. Electron physician, 2017, 9, 3584.

17. F. Öztürk, M. Ersöz, S.A. Öztürk, E. Hatunoğlu, S. Malkoç. European Journal of Orthodontics, 2016, 38, 163.

18. K. Zarrinnia, N.M. Eid, M.J. Kehoe, American Journal of Orthodontics and Dentofacial Orthopaedics, 1995, 108, 284.

19. M. Fjeld, B. Øgaard, American Journal of Orthodontics and Dentofacial Orthopaedics, 2006, 130, 575.

20. E. İşman, E.S. Karaarslan, R. Okşayan, A.R. Tunçdemır, S. Üşümez, N. Adanir, M.A. Cebe, Dental Materials Journal, 2012, 31, 947. 